\title{
Climate finance in an age of uncertainty
}

\author{
Timothy Cadman* \\ Institute for Ethics, Governance and Law, Griffith University, 170 Kessels Road, Nathan, Queensland 4111, \\ Australia
}

(Received 27 July 2014; accepted 9 August 2014)

There was a great deal of uncertainty inside the discussions held in Bonn, Germany, 4-14 June in preparation for the UN Framework Convention on Climate Change negotiations later this year in Lima, and in Paris in 2015. This hinged upon what will be contained in the new institutional arrangements for reducing emissions, to be developed in the second commitment period, which replaces the Kyoto Protocol. At the time of writing, it is not yet clear exactly what mechanisms will be put in place. The old architecture favoured marketdriven mechanisms, but an ongoing alternative viewpoint that favours non-market-based approaches gained some traction, notably in discussions relating to REDD + . What is not clear is whether this is because developing countries object philosophically to the use of capital markets to stimulate emission reduction through forests, or because the current price of carbon is so low at present. There was also a considerable degree of jockeying for power regarding future funding mechanisms within the next commitment period. The Global Environment Facility has previously played a key role in managing, channelling, and disbursing developed country donor contributions via a multitude of funds, to developing countries. The Green Climate Fund, a product of the Conference of Parties 16 in Cancun (2010), is now likely to be the lead fund for climate action. It is difficult to tell if these developments will contribute anything substantive enough to reduce emissions by the necessary amount required to avoid dangerous human-induced climate change.

Keywords: climate change; climate finance; carbon markets; sustainable development; governance

\section{Background}

The world is currently set on a dangerous path, where anthropogenic climate change has succeeded in increasing global mean temperatures by approximately one degree Celsius. This is likely to reach four to six degrees by the end of the century, given the current rates of greenhouse gas emissions. Signatories to the climate convention acknowledged back in 2009 that an increase above two degrees would exceed safe thresholds. Humanity is approaching that level, so it is imperative that global governments take decisive action in the climate negotiations in Lima in December this year, and finalise arrangements in Paris in 2015. At present, global per capita emissions are at around 5 tonnes of carbon dioxide per person, resulting in total emissions of approximately 36 billion tonnes. To stay under the two degrees safety limit, emissions will have to be drastically reduced to no more than 13 billion tonnes per capita, and the policy community will have to factor in an increasing global population. At the same time, as the global population

\footnotetext{
*Emails: tim.cadman@griffith.edu.au,t.cadman@griffith.edu.au
} 
increases by $40 \%$, according to predictions, emissions will need to go down by roughly twothirds. Five tonnes of $\mathrm{CO}_{2}$ per capita will have to be reduced to not more than one and a half tonnes by 2050. The degree of transformation that energy-intensive developed countries will require is daunting. US emissions in 2010 were 18 tonnes per capita. No major developed economy is on the path to reduce emissions down to the levels required (Sachs et al. 2014).

\section{The future of emissions trading}

The uncertainty in the climate negotiations held in Bonn this June as part of the UN Framework Convention on Climate Change (UNFCCC) largely concerned the nature of the future design of the policy instruments for reducing emissions that will be put in place in the next second commitment to replace the Kyoto Protocol (KP). In the first period, 37 of the highest emitting and most developed countries made commitments to reduce emissions to $5 \%$ below the 1990 levels. The commitment of an 18\% reduction for the new period 2013-2020 is more ambitious (UNFCCC 2014a). Whether it is realistic is questionable. Global emissions have increased by approximately $50 \%$ on the 1990 levels. In the case of China, for example, emissions have risen by over $280 \%$ (Harvey 2012).

A number of countries have increased their gross domestic product and/or industrialised since the Protocol came into force. New countries now have the potential to sign up (UNFCC 2014b). It will be interesting to see which of these, particularly the 'BRICS' (Brazil, Russia, India, China, South Africa) sign up, whether the USA will do likewise, and which of the previous signatories will re-commit. In Bonn, the signs were not good. It appeared that Canada and Australia - not surprisingly, given their joint co-operation on expanding fossil fuel production - would not. Australia's removal of the price on carbon is a further sign of weakening commitment, almost hostility, to reducing emissions. At this stage, Europe appears to be the only significant bloc of support.

What was also not clear in Bonn was what mechanisms will be put in place to reduce emissions. The previous architecture was built around market-driven mechanisms, the Clean Development Mechanism (CDM), Joint Implementation (JI), and International Emissions Trading (see Figure 1). These 'flexible mechanisms' were designed to encourage market-based actions around reducing emissions, and act as a placeholder while global negotiations continued. The CDM was largely for developing countries that did not sign up to emission reduction targets, but could still generate Certified Emission Reductions, suitable for emissions trading, available for purchase by developed countries to 'offset' their emissions through purchasing credits from CDM projects in developing countries (Cadman 2014, 1-2). The JI was created for developed countries that have agreed to emission reductions (the so-called Annex B countries), to develop projects in partner Annex B countries (UNFCCC 2014c).

Both schemes generate emissions reduction units, suitable for trading, the objective being to stimulate emission trading, and emission trading schemes. However, both the CDM and JI were deeply affected by the GFC (Kawai 2010). It is ironic that the crisis slowed industrial growth, and therefore those emissions that needed to be reduced. Simultaneously, the market was awash with credits as the CDM in particular was so successful in terms of uptake, resulting in over 7000 projects by 2013, with the number of credits issued being equivalent to 1.2 billion tonnes of carbon (CDM 2014). With insufficient buyers to purchase credits, lack of scarcity lowered the price. In a sense, the CDM was a victim of its own success. The talk in Bonn in the CDM 'camp' was to encourage holders of certificates to simply tear them up, as a sign of their 'green' good faith, and for all countries and companies to commit to a new mechanism that would reduce emissions without offsets. Sadly, the real value of the CDM has been lost in the criticism over price. As one senior retiring figure in the CDM commented in Bonn, the CDM was incredibly successful in 


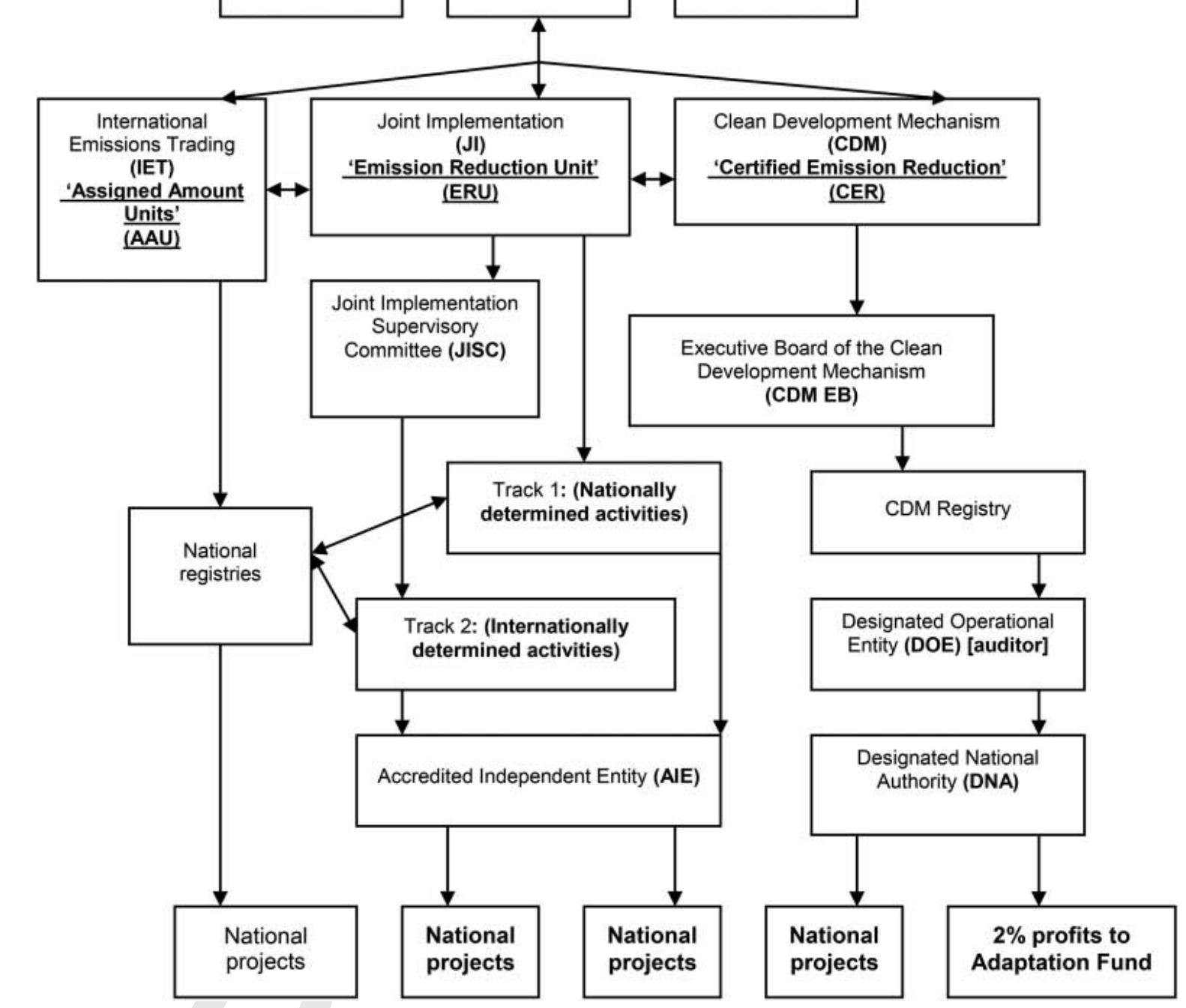

Figure 1. The flexible mechanisms under the KP of the UNFCCC (as of 3 June 2014).

terms of its capacity building around estimating, measuring, and verifying emissions reductions, not so much in the economic value of CERs. It was because it allowed those countries that were seriously committed, particularly in Europe, to meet their reduction targets, even if this was by offsetting them by purchasing reductions elsewhere.

But with an end to the KP, and the 'failure' of putting a sufficiently attractive price on carbon, the value of using the market to drive the reduction of emissions is itself under attack. A significant bloc of developing countries, largely from Latin America, and led by Bolivia, object to the marketisation of emissions (Lawrence 2014, 156-157). In Bonn, the talk was all about 'payments 
for ecosystem services' (PES), an approach that effectively provides payments to countries with forests not to cut them down. This is fine in theory, but the other disturbing development in Bonn was that countries favouring PES, notably Brazil, were also arguing that there would be no need for the same levels of monitoring, reporting, and verification required under emission trading systems, as there would be no carbon price. The very architecture that made the CDM so credible as a mechanism would no longer be necessary. But what accounting system will replace it, and how will the world know that emissions are being reduced? This is not known at present.

\section{Market or non-market: the future for REDD+}

The most significant 'replacement' to the flexible mechanisms, and is now caught between these opposing approaches, is the initiative to reduce emissions from deforestation and forest degradation in developing countries, known as 'REDD+' (Cadman and Maraseni 2013). REDD+ has been the subject of the climate negotiations for several of the most recent Conferences of the Parties (COP) to the climate convention. As of November 2013, significant amounts of funding have been provided by donor countries on pilot REDD+ schemes - US\$ 906.5 million since 2008, according to one calculation (Caravani et al. 2013). This initiative is therefore likely to remain the fulcrum for the 'non-market/market mechanisms' debate, which will be taking place at COP 20, to be held in Lima in December this year, and as the world awaits the outcomes of COP 21 where the arrangements for the 2015-2020 period, and beyond, will be finalised (if the Parties can agree).

The discussions around the financing and future design of REDD + replay an ongoing developed/developing country conflict, otherwise known as the 'North/South divide'. Developing countries want to de-couple finance for development from neo-liberal market ideology. In the case of REDD+, the main countries in Bonn pushing this position were not solely from Latin America, but the Asia Pacific as well, and including Indonesia, which echoed similar sentiments regarding market mechanisms. Developing countries, who often coalesce around a bloc referred to as the G77 (representing the poorest countries, and cocking a snoop at the G7), wanted assurances in Bonn that funds for reducing emissions would be linked to PES for the carbon sequestration value of forests, and for avoided deforestation/degradation.

Again, it is not entirely clear if all developing countries in the 'non-market bloc' object to the use of capital markets to encourage emission reduction through forest investments on philosophical grounds, or simply because carbon prices are so low. In the European market, it has been estimated that a carbon price of $€ 30$ a tonne is necessary to encourage investment. In 2008, the price was $€ 28$, but by January 2013, this had plummeted to less that $€ 4$ (Ares 2014). With such low prices, developing (largely tropical rainforest) countries may feel that a straight out 'fee for service' from climate funds is a better option than waiting for markets to stabilise at a better price. But this locks climate finance into a vicious cycle. If reductions in emissions are separated from market forces, payments look like subsidies, which will continue to make private finance wary of investment in emissions trading, which in turn means that prices are likely to stay low. This means that developing countries ('recipient Parties' in UN parlance) will continue to rely on donor governments ('contributing Parties'), which raises questions over the durability of any projects funded, given the problem of donor fatigue (Hamilton and Fay 2009). Without significant private sector investment, as one participant in Bonn speculated, funding will amount to little more than corporate philanthropy under the guise of social responsibility, with little prospect of permanence.

Governments that fund the climate funds are not particularly enthralled by this prospect, and would rather build the capacity of market mechanisms to reduce emissions. In Bonn, responding to Bolivia's insistence on non-market mechanisms, the USA tried to be conciliatory, suggesting 
that there could be a place for PES in a 'mixed economy' of non-market/market mechanisms. But the EU may prove to be less tractable. Given that it has invested so much in building its own emission trading infrastructure, and is one of climate finance's largest donors, it is unlikely to change its stance. This entrenches resentment in the recipient countries, and so the cycle is reinforced. Returning to the observation that carbon markets are soft, and prices are low, could it be that prices are neither the consequence of lack of demand, nor the abundance of credits, but the fact that the policy signals are so unclear?

\section{Duelling climate funds?}

Since its foundation in 1991, the Global Environment Facility (GEF) has been central to the management and distribution of donor country contributions to enable sustainable development, and the climate adaptation and mitigation initiatives that have emerged under the Convention. GEF played an important part in the UN Conference on Environment and Development of 1992 (UNCED - the Rio 'Earth Summit'), and subsequently in Rio +10 (2002), and Rio +20 (2012). Funds allocated by the GEF are implemented via on-the-ground projects in recipient countries. Implementing agencies include multilateral development banks, such as the World Bank and the European Investment bank, as well as government agencies such as Norway's NORAD (a large investor in REDD+). Partners on the ground, often UN agencies like the UN Environment Programme, collaborate with both governmental and non-governmental organisations that manage the projects.

GEF allocates funds over multi-year cycles, targeting a number of UN environment-related programmes under the Convention on Biodiversity, as well as climate change, including the Special Climate Change Fund (SCCF) and the Least Developed Countries Funds (LDCF), as well as multi-focal activities that include climate change-related elements (GEF 2014).

Climate finance is immensely complex and perpetually evolving. But a new challenger has arisen to replace GEF as the dominant force in climate finance - the Green Climate Fund (GCF), an outcome of negotiations at COP 16 in Cancun (2010) (UNFCCC 2014d). It is not uncommon in intergovernmental regimes for new instruments to be introduced with a loud fanfare, bringing into question the ongoing viability of existing instruments. The GCF is likely to be the next big thing in climate finance. Rumour in Bonn had it that The GEF's funds, including and LDCF and SCCF, might be adopted by GCF, which would become the principle climate fund, relegating GEF to the sidelines of climate finance. There was also talk of streamlining the procedures for allocating funds to this emerging 'mega-fund'. Simplicity would be a good idea, but there are also perils. In REDD+, for example, this author knows of funds spent on pilot projects that went to providing goats to compensate communities for restricting access to "carbon storage' forests: goats that browsed the vegetation outside trial areas - thereby increasing deforestation and forest degradation - surely a perverse outcome? Whatever happens to GEF at the hands of GCF, what matters most is that the governance quality of funds management and the implementation of projects are not undermined. Efficiency and simplicity are not trade-offs for accountability and transparency or the many other elements of 'good' governance necessary for climate finance to retain its integrity.

\section{Concluding observations}

On the basis of developments in Bonn this June, it remains unlikely that world governments are ready to negotiate the sort of agreement required in Paris in 2015. Politics looks set to predominate and result in a shallow agreement, not deep enough to fundamentally decarbonise national economies. The very architecture that delivered emission reductions at scale is under serious 
attack, and suggested alternatives do not look promising at this stage. Climate finance itself looks set to be radically transformed, and again, existing well-functioning architecture like the GEF is to be replaced by a new mechanism that promises to channel mega-money into greenhouse gas emissions, but is as yet untested. Analysis: no cause for optimism at this stage.

\section{References}

Ares, S. 2010. Carbon Price Floor: Support and Certainty for Low-Carbon Investment. London: HM Treasury.

Cadman, T. 2014. "Introduction: Climate Change and Global Policy Regimes." In Global Climate Change Policy: Towards Institutional Legitimacy, edited by T. Cadman, 1-16. London: Palgrave Macmillan.

Cadman, T., and T. Maraseni. 2013. "More Equal than Others? A Comparative Analysis of State and NonState Perceptions of Interest Representation and Decision-Making in REDD+ 26/07/2014.negotiations." Innovation: The European Journal of Social Science Research 26 (3): 214-230.

Caravani, A., S. Nakhooda, C. Watson, W. McFarland, and L. Schalatek. 2013. "Climate Finance Thematic Briefing: REDD+ Finance.” Climate Finance Fundamentals 5. Accessed July 26, 2014. http://www.odi. org.uk/sites/odi.org.uk/files/odi-assets/publications-opinion-files/8676.pdf.

CDM. 2014. "News Release: Kyoto Protocol's Clean Development Mechanism Reaches Milestone at 7,000 Registered Projects." Accessed July 26, 2014. http://cdm.unfccc.int/CDMNews/issues/issues/I 8XM9FF99N0WN7MMK9XFBJLSX23LX8Q/viewnewsitem.html.

GEF. 2014. “Areas of Work.” Accessed July 26, 2014. http://www.thegef.org/gef/Areas_work.

Hamilton, K., and M. Fay. 2009. "A Changing Climate for Development." Finance \& Development 46 (4): $10-12$.

Harvey, F. 2012. "The Kyoto Protocol is not Quite Dead. The Guardian 26/11/2012.” Accessed July 26, 2014. http://www.theguardian.com/environment/2012/nov/26/kyoto-protocol-not-dead.

Kawai, M. 2010. "The Global Financial Crisis and Subregional Economic Cooperation in Northeast Asia." ERINA Report 93, 75-89. Accessed July 26, 2014. http://www.erina.or.jp/en/Ec/2010nice/keynotee. pdf.

Lawrence, P. 2014. Justice for Future Generations: Environment Discourses, International Law and Climate Change. Cheltenham: Edward Elgar.

Sachs, J., L. Tubiana, E. Guerin, H. Waisman, C. Mas, M. Colombier, and G. Schmidt-Traud. 2014. "Pathways to deep Decarbonisation." Institute for Sustainable Development and International relations (IDDRI) and Sustainable Development Solutions Network (SDSN).

UNFCCC. (2014a). "Doha Amendment." Accessed July 4, 2014. http://unfecc.int/kyoto protocol/doha amendment/items/7362.php.

UNFCCC. (2014b). “Kyoto Protocol.” Accessed July 4, 2014. https://unfccc.int/kyoto_protocol/items/2830. php.

UNFCCC. (2014c). “Joint Implementation JI.” Accessed July 26, 2014. http://unfccc.int/kyoto_protocol/ mechanisms/joint_implementation/items/1674.php.

UNFCCC. (2014d). “Green Climate Fund.” Accessed July 26, 2014. http://unfccc.int/cooperation_and support/financial_mechanism/green_climate_fund/items/5869.php. 